\title{
Imigração e redes de acolhimento: o caso dos haitianos no Brasil
}

\author{
Sidney Antonio da Silva*
}

Este trabalho tem como objetivo analisar o papel das redes de acolhimento no processo migratório dos haitianos no Brasil, procurando entender a razão pela qual tais redes tiveram uma centralidade na gestão dessa imigração e na interlocução das questões por ela engendradas no país e, ao mesmo tempo, balizar o papel que elas tiveram para facilitar a mobilidade desses migrantes internamente, além de retroalimentar o fluxo migratório, iniciado de forma expressiva em 2010. Partindo de dados coletados na fronteira, em Manaus e em algumas cidades brasileiras, onde foram aplicados 279 questionários, que reúnem informações acerca dos migrantes haitianos presentes no Brasil, bem como da família ausente, seja no Haiti ou em outro país, foi possível levantar a hipótese de que, sem essas redes de acolhimento, a chegada e os percursos desses imigrantes pelo Brasil teriam sido muito mais dramáticos do que realmente foram, em razão da falta de políticas públicas de acolhimento e de inserção sociocultural.

Palavras-chaves: Imigração haitiana. Redes migratórias. Acolhimento. Brasil.

\footnotetext{
*Universidade Federal do Amazonas (Ufam), Manaus-AM, Brasil (sidsilva@ufam.edu.br).
} 


\section{Introdução}

A chegada de um grupo de haitianos na tríplice fronteira norte do Brasil (TabatingaAM), no início de 2010, causou surpresa a todos, pois, se a emigração não é uma novidade na história migratória do Haiti, em território brasileiro sua presença constituía um fato novo, que foi assumindo diferentes significados, à medida que tal fluxo foi aumentando nas fronteiras brasileiras. Num curto espaço de tempo, esses imigrantes se encontravam em todos os estados do Norte e Centro-Sul do Brasil, ou pelo menos por ali passaram, inserindo-se em diferentes atividades do mercado de trabalho.

Contudo, cabe indagar em que medida as redes privadas de acolhida, confessionais ou laicas, tiveram um papel central na gestão da imigração haitiana no Brasil e, como decorrência dessa atuação, balizar se essas redes teriam sido também um agente facilitador da mobilidade de haitianos pelo território brasileiro. Vale notar que, nesse sentido, será priorizada a atuação da rede de acolhida da Igreja Católica, denominada Pastoral do Migrante, já que essa organização está presente em várias cidades brasileiras, desde o Norte, passando pelo Centro-Oeste, o Sudeste até o Sul do Brasil. Como tal, cabe analisar os múltiplos significados de sua atuação, visando ampliar a discussão sobre a posição do Estado brasileiro no campo migratório atual.

Com o objetivo de tentar responder a essas indagações, o presente artigo propõe-se a tecer algumas considerações sobre o papel estratégico das redes de acolhimento institucionalizado nos locais de recepção da imigração haitiana, relacionando-as com outras redes, entre elas, aquelas constituídas pelos próprios imigrantes, as quais podem anteceder ou se formar em função de novos fluxos migratórios. Além dessas redes, devem ser consideradas ainda aquelas que se formam exclusivamente com a finalidade de operacionalizar fluxos migratórios, como é o caso das agências de viagens ou dos “coyotes", agentes facilitadores da travessia nas fronteiras.

Nessa perspectiva, o conceito de redes migratórias tem sido usado de forma mais genérica para dar conta de processos que envolvem, segundo Massey (1988, p. 396), “laços interpessoais que ligam migrantes, migrantes anteriores e não-migrantes nas áreas de origem e de destino, por meio de vínculos de parentesco, amizade e conterraneidade". Embora diferentes redes possam estar imbricadas em processos migratórios, vale notar que cada uma delas tem finalidades específicas e formas estratégicas de atuação. Contudo, trabalhamos com a hipótese de que tanto redes sociais quanto migratórias, bem como redes de acolhimento, exercem um papel central na manutenção e direcionamento de fluxos migratórios, pois, segundo Tilly (1990, p. 84), “não são os indivíduos que emigram, mas sim a rede”.

É evidente que as pessoas migram por diferentes motivos, mas o fazem como partícipes de um processo social mais amplo que, no caso dos haitianos, parece apontar, sobretudo, para um empreendimento predominantemente familiar, seja da família nuclear ou ampliada, com suas implicações no âmbito das lealdades pessoais e grupais, que se transformam em compromissos morais de retribuir a quem contribuiu um dia para a sua partida. 


\section{A imigração haitiana e suas redes}

Diferentes trabalhos já apontaram as motivações e circunstâncias da imigração haitiana para o Brasil, lançando luzes para a compreensão de um fluxo migratório que, apesar de novo no país, faz parte de um processo mais amplo de circulação de pessoas, de capital e de mercadorias (BAENINGER, 2016, p. 15).

$\mathrm{Na}$ tentativa de identificar um possível perfil dessa imigração, diferentes bases de dados já foram construídas e analisadas, entre elas, a dos registros da Polícia Federal sobre a entrada de estrangeiros no Brasil (Sistema Nacional de Cadastro e Registro de Estrangeiros - Sincre/PF), produzida por Fernandes e Faria (2016). Tais dados apontam para uma população com idade média de 31,7 anos, sendo que a maioria (70\%) se concentra entre as faixas etárias de 25 a 39 anos. Com relação ao sexo, verifica-se que os homens ainda constituem o maior contingente, embora a proporção de mulheres venha aumentando nos últimos anos, chegando a $40 \%$ em 2015, fato que pode indicar um processo de reunificação familiar (FERNANDES; FARIA, 2016, p. 106).

Outro levantamento de dados, de caráter qualitativo, com entrevistas intencionais com imigrantes selecionados, foi realizado pelo Grupo de Estudos Migratórios na Amazônia (Gema), entre 2014 e 2015, em conjunto com os Observatórios das Migrações da Universidade Estadual de Campinas (Unicamp), da Fundação Universidade Federal de Rondônia (Unir) e da Universidade do Estado de Santa Catarina (Udesc). Esta abordagem permite identificar especificidades do grupo estudado, além de propor um possível perfil dos haitianos entrevistados, num total de 279. Entre as questões levantadas, nos sete módulos do questionário aplicado, destacam-se: formas de inserção no mercado de trabalho; a importância das remessas para as famílias no Haiti; o papel das redes sociais e migratórias na manutenção do fluxo migratório; os possíveis canais de integração com a sociedade local; e a visão desses imigrantes sobre a atuação da Pastoral e do visto humanitário, bem como a posição do governo brasileiro nessa questão. 0 levantamento foi realizado em seis Unidades da Federação (São Paulo, Amazonas, Rondônia, Paraná, Santa Catarina e Rio Grande do Sul), envolvendo nove municípios, inclusive as capitais dos respectivos Estados. Além dos questionários aplicados com os imigrantes, foram feitas entrevistas abertas com representantes da Pastoral do Migrante de Manaus, São Paulo e Porto Alegre, entre 2015 e 2016.

De acordo com este levantamento, é possível visualizar imigrantes mais jovens, com idades abaixo dos 18 anos, e pessoas com mais de 50 anos, sendo que a média etária ficou em torno de 29 anos, como pode ser constatado no Gráfico 1.

Com relação ao sexo, observa-se maioria expressiva de homens, com $86,4 \%$ dos haitianos captados em pesquisa de campo, o que tem se mantido desde o início do fluxo migratório, com pequenas variações. 0 mesmo aconteceu com o contingente feminino, com 13,6\%. Dados levantados pela Pastoral do Migrante de Tabatinga (AM) apontam semelhanças, pois, dos 2.842 haitianos que entraram por aquela fronteira em $2011,85,46 \%$ eram 
homens e $14,11 \%$ eram mulheres. Naquele ano, já fora constatada também a presença de 12 menores (COSTA, 2015, p. 66). Contudo, de acordo com a base de dados do Sincre/PF, analisada anteriormente por Fernandes e Faria (2016), a presença feminina vem aumentando ao longo dos anos, fato que, além de indicar um processo de reunificação familiar, pode estar revelando o papel das redes sociais e migratórias nesse fluxo.

\section{GRÁFICO 1}

Haitianos captados em pesquisa de campo, por grupos etários, segundo condição de presença - 2014-2015

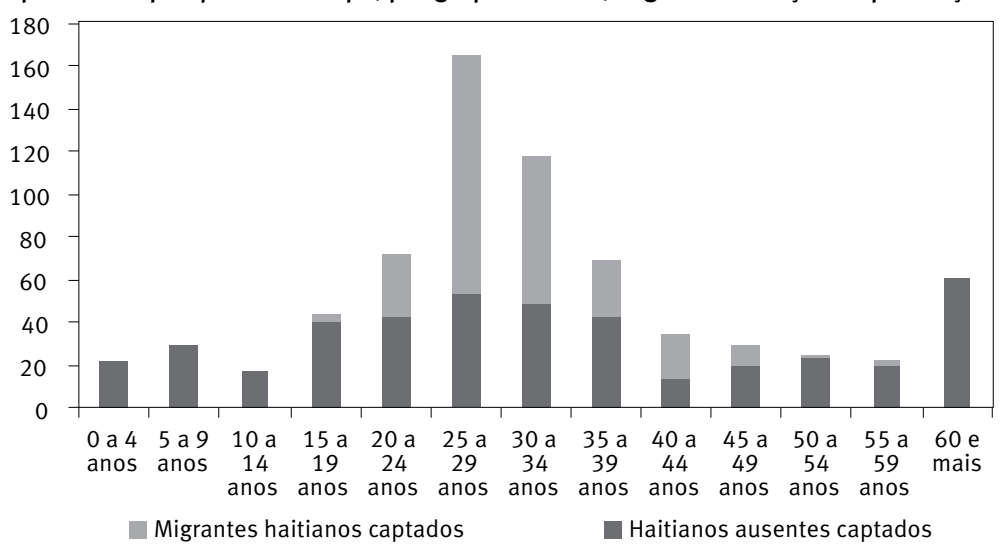

Fonte: Projeto Temático Observatório das Migrações em São Paulo (Fapesp/CNPq/Nepo/Unicamp); Grupo de Estudos Migratórios na Amazônia (CNPq/Ufam); Observatório das Migrações de Santa Catarina (CNPq/Udesc); Observatório das Migrações de Rondônia (Unir). Pesquisa de Campo, 2014-2015.

Do ponto de vista do status conjugal, verifica-se predominância dos solteiros em relação aos casados (Tabela 1), embora muitos dos que se declararam solteiros afirmassem ter filhos ou algum tipo de relação conjugal no Haiti. Este é um fato que leva a problematizar a ideia de status conjugal, pois a condição de casado não depende apenas de se estar oficialmente unido a alguém.

TABELA 1

Imigrantes haitianos entrevistados em pesquisa de campo, segundo status conjugal - 2014-2015

\begin{tabular}{lcc}
\hline Status conjugal & N & \% \\
\hline Solteiro(a) & 166 & 59,5 \\
Casado(a) & 90 & 32,3 \\
Unido(a) & 13 & 4,7 \\
Separado(a) & 2 & 0,7 \\
Viúvo(a) & 2 & 0,7 \\
Não respondeu & 6 & 2,2 \\
Total & $\mathbf{2 7 9}$ & $\mathbf{1 0 0 , 0}$ \\
\hline
\end{tabular}

Fonte: Projeto Temático Observatório das Migrações em São Paulo (Fapesp/CNPq/Nepo/Unicamp); Grupo de Estudos Migratórios na Amazônia (CNPq/Ufam); Observatório das Migrações de Santa Catarina (CNPq/Udesc); Observatório das Migrações de Rondônia (Unir). Pesquisa de Campo, 2014-2015.

Com relação à escolaridade, a maioria possui mais de dez anos de estudos, o que equivale ao ensino médio no Brasil (Tabela 2). Isso parece indicar um fluxo com um percentual 
relevante de pessoas qualificadas, já que muitos deles afirmaram ter concluído ou começado um curso superior no país de origem ou de imigração antes de virem ao Brasil, como é o caso da República Dominicana.

TABELA 2

Imigrantes haitianos entrevistados em pesquisa de campo, segundo anos de estudo - 2014-2015

\begin{tabular}{lrr}
\hline Anos de estudo & N & \% \\
\hline Menos de 1 ano & 1 & 0,4 \\
De 1 a 3 anos & 6 & 2,2 \\
De 4 a 7 anos & 36 & 12,9 \\
De 8 a 10 anos & 54 & 19,4 \\
Mais de 10 anos & 176 & 63,1 \\
Não sabe/não respondeu & 6 & 2,2 \\
Total & $\mathbf{2 7 9}$ & $\mathbf{1 0 0 , 0}$ \\
\hline
\end{tabular}

Fonte: Projeto Temático Observatório das Migrações em São Paulo (Fapesp/CNPq/Nepo/Unicamp); Grupo de Estudos Migratórios na Amazônia (CNPq/Ufam); Observatório das Migrações de Santa Catarina (CNPq/Udesc); Observatório das Migrações de Rondônia (Unir). Pesquisa de Campo, 2014-2015.

Já em relação aos recursos que viabilizaram a viagem, grande parte dos entrevistados (43\%) sinalizou que a financiaram com recursos próprios. Isso pode indicar que eles já haviam acumulado recursos, mediante outras emigrações, seja no próprio Caribe ou para a América do Norte. Contudo, respostas que apontaram a participação da rede familiar também são significativas, totalizando $44 \%$ dos entrevistados. Se acrescentarmos as respostas que indicaram o apoio de um amigo, essa porcentagem chega a 49,09\%. Nesse sentido, o apoio do grupo familiar ou de um amigo, antes da partida ou durante o trajeto, foi fundamental para chegar ao destino proposto. Quando a família não dispõe de recursos necessários para o empreendimento, a solução tem sido recorrer a financiamentos ou vender um imóvel, fato que torna a situação do imigrante ainda mais dramática, caso ele não consiga inserir-se rapidamente no mercado de trabalho do país de "destino".

Se, por um lado, as redes de ajuda mútua são fundamentais para viabilizar o empreendimento migratório, por outro, a chegada de milhares de haitianos na fronteira norte brasileira contou também com a existência de redes migratórias preexistentes, como é o caso da rede Haiti-Equador. Naquele país já havia a presença de haitianos antes mesmo da catástrofe de 2010, por ser considerado um "país aberto", ou seja, que não exige visto de entrada (HANDERSON, 2015, p. 197; MAMED; LIMA, 2016, p. 118).

Já no caso brasileiro, era necessário ter um visto de entrada, que seria emitido pela embaixada brasileira de Porto Príncipe. Porém, com o aumento da demanda, o tempo de espera por um visto passou a ser um complicador dos planos de quem pretendia emigrar, além do custo para a sua emissão, considerado alto naquele contexto de calamidade social. Assim, cobrados pela urgência de trabalhar e enviar recursos aos seus familiares, muitos haitianos(as) tiveram que contar com a mediação de ajans, agências que preparavam a viagem, comprando as passagens e fornecendo informações sobre a longa rota que se criou para chegar à fronteira brasileira, seja em Tabatinga (AM) ou Brasiléia (AC). 
Segundo Handerson (2015), há uma diferença entre agência e raketè, pois enquanto a primeira, mesmo que superfaturando os gastos da viagem, presta um serviço profissional ao viajante, ocupando-se dos preparativos da viagem e fornecendo-lhe informações para o trajeto, o segundo, além de explorá-lo, age de má fé, prometendo coisas que não poderão ser cumpridas e muitas vezes o abandona no meio do caminho.

Ao chegarem à fronteira brasileira, primeiro em Tabatinga (AM) e depois em Brasiléia (AC), muitos imigrantes já não dispunham de recursos, nem mesmo para as necessidades básicas. Outros chegavam debilitados e doentes. Contudo, em Tabatinga, outro drama começaria em razão da longa espera para serem atendidos no posto da Polícia Federal (SILVA, 2012, p. 305). Aqueles que ainda tinham algum recurso alugaram casas e quartos, que foram compartilhados entre familiares e amigos; quem não tinha teve que contar com o apoio humanitário da Igreja Católica, que arcou com o ônus da acolhida naquela cidade. Igrejas evangélicas também participaram, porém, oferecendo apenas seus espaços para o culto em língua materna.

Já em Brasiléia (AC), o atendimento destes imigrantes ficou por conta do governo estadual em parceria com o governo federal, que os alojou num galpão sem infraestrutura adequada para atender cerca de 1.000 pessoas, quando sua capacidade seria de no máximo 300 (MAMED; LIMA, 2016, p. 143). Depois de várias denúncias de entidades religiosas sobre a situação precária do alojamento e de matérias veiculadas em jornais de grande circulação nacional sobre a forma como esses imigrantes eram acolhidos naquela fronteira, o alojamento foi fechado e transferido para uma chácara na periferia de Rio Branco, em junho de 2014, mais um lugar de passagem até chegarem no “destino" pretendido, a cidade de São Paulo (MAMED; LIMA, 2016, p. 144).

Para além das redes oficiais de acolhida, marcadas em geral pelo improviso e precariedade, vale ressaltar também a vitalidade das redes de ajuda mútua nos locais de recepção, cujo apoio foi decisivo na inserção daqueles que chegavam sem moradia e não dominavam o idioma local. Nesse sentido, os laços de solidariedade, apoiados em vínculos familiares e de conterraneidade no interior das redes migratórias, podem ser marcados tanto pela fragilidade quanto pela força. Segundo Truzzi (2008, p. 212), por um lado:

[...] o capital social de solidariedade, que produz sustentação mútua entre os integrantes da rede, pode ser alto, mas, em muitos casos, conspícuo. De outro lado, o capital social de reciprocidade, derivado das relações tecidas externamente à rede, com outros grupos, e muitas vezes crucial à mobilidade social, é débil.

Dados captados na referida pesquisa indicam que a solidariedade interna à rede foi fundamental nesse processo migratório. É certo que grande parte desses migrantes afirmou ter se ajeitado sozinho (94 casos), enquanto outros disseram ter contado com a ajuda de amigos (73 casos), ou ainda ter recebido auxílio de algum parente (28 casos). Embora apenas 28 entrevistados tenham afirmado que receberam alojamento na Pastoral do Migrante, sabe-se que o número dos atendidos foi bem maior, pois, em Manaus, salões de igrejas e várias casas foram improvisadas ou alugadas para recebê-los (COSTA, 2016, 
p. 31). A aparente disparidade entre os dados coletados e a ampla e conhecida atuação da Pastoral no acolhimento dos haitianos pode estar relacionada, em primeiro lugar, ao caráter emergencial do alojamento, pois, diante da quantidade de imigrantes que chegavam, seja em Manaus, seja em São Paulo, era preciso dar uma resposta rápida, ainda que limitada. Em segundo lugar, é preciso considerar a circularidade destes imigrantes pelo Brasil, em razão da urgência de se inserir no mercado de trabalho. Assim, no momento da coleta de dados, eles já não se encontravam mais na Pastoral. Na verdade, muitos passaram pela Pastoral para buscar alguma forma de assistência, como, por exemplo, preencher a ficha para pedir a carteira de trabalho (COSTA, 2016, p. 37). Adiante se mostrará a diversidade da assistência a que se podia recorrer na Pastoral, justificando essa afirmativa.

De forma análoga, quando indagados com quem vieram viver no Brasil, grande parte desses imigrantes respondeu que seria sozinho (Tabela 3), informação que pode ser questionada, pois, sem recursos ou emprego num primeiro momento, seria difícil terem condições para alugar um imóvel por conta própria. É mais provável que a utilização da rede familiar e de amizade tenha sido acionada em maior grau do que foi declarado pelos entrevistados. 0 fato de terem mencionado um(a) amigo(a) indica que a rede de apoio pode ir além dos laços de parentesco.

TABELA 3

Imigrantes haitianos entrevistados em pesquisa de campo, segundo a pessoa com quem veio viver no Brasil - 2014-2015

\begin{tabular}{lcc}
\hline Com quem veio viver no Brasil & N & \% \\
\hline Sozinho & 145 & 51,97 \\
Amigo(a) & 50 & 17,92 \\
Outro parente & 35 & 12,54 \\
Cônjuge & 29 & 10,39 \\
Irmão/irmã & 13 & 4,66 \\
No abrigo da Pastoral do Migrante & 3 & 1,08 \\
No abrigo da Igreja Evangélica & 2 & 0,72 \\
Pai & 1 & 0,36 \\
Outros & 1 & 0,36 \\
Total & $\mathbf{2 7 9}$ & $\mathbf{1 0 0 , 0}$ \\
\hline
\end{tabular}

Fonte: Observatório das Migrações em São Paulo (Fapesp/CNPq/Nepo/Unicamp); Grupo de Estudos Migratórios na Amazônia (CNPq/Ufam); Observatório das Migrações de Santa Catarina (CNPq/Udesc); Observatório das Migrações de Rondônia (Unir). Pesquisa de Campo, 2014-2015.

Já na busca do primeiro emprego, as redes familiares parecem ter tido menor incidência, isto porque os recém-chegados ainda não dominavam os códigos culturais e as exigências do mercado de trabalho locais, fazendo-se necessária a mediação de instituições, como é o caso da Pastoral do Migrante e de outras ONGs não confessionais, que foram fundamentais para encaminhá-los para o primeiro emprego, bem como para facilitar suas trajetórias pelo Brasil. Os números captados na pesquisa sobre esta questão parecem também modestos, pois apenas 28 entrevistados apontaram a mediação da Pastoral para a inserção no mercado de trabalho. Entretanto, dados da Pastoral do Migrante de Manaus apontam que, 
somente em 2012, foram encaminhados para o trabalho em outros Estados brasileiros 1.021 haitianos, sendo o Paraná o Estado que mais recebeu trabalhadores, totalizando 597, seguido pelo Rio Grande do Sul, com 337 (COSTA, 2016, p. 41).

E nessa circulação de propostas de emprego, vale ressaltar o papel das redes de informações criadas pelos próprios imigrantes, particularmente na Internet, em que tais informações circulam em tempo real, contribuindo para autorregular o sistema, uma vez que "cada informação sobre um indivíduo em trajetória influencia o sistema como um todo". (TRUZZI, 2008, p. 206). Contudo, segundo o mesmo autor, é preciso balizar o grau de confiabilidade atribuída a tais informações, uma vez que, no caso das imigrações "históricas", aquele que "pensava em emigrar tendia a confiar mais nas informações fornecidas ao vivo ou por carta, por um vizinho ou amigo, por exemplo, do que por folhetos de propaganda distribuídos por um agente recrutador" (TRUZZI, 2008, p. 206).

Se é verdade, por um lado, que informações sobre o país de destino ou passagem, veiculadas pelas redes sociais, podem preexistir às redes migratórias, sendo consideradas mais "confiáveis" do que outras, por outro, não se pode negar também o poder de influenciar a decisão de emigrar exercido por agenciadores, que vendem uma "ilusão migratória", desmitificada tão logo o imigrante cruze a fronteira de seu próprio país.

Tal “ilusão" ou, mais precisamente, representações sobre o país de imigração puderam ser comprovadas nas entrevistas, pois, quando se perguntava o que eles sabiam sobre o Brasil antes de terem saído do Haiti, as imagens mais recorrentes eram as dos grandes centros urbanos como as cidades do Rio de Janeiro e São Paulo, ou ainda que o Brasil tinha belas praias e muito futebol. A cidade de Manaus não fazia parte deste imaginário. A dura realidade que tiveram que enfrentar, já na fronteira amazônica, era muito diferente daquela que lhes fora apresentada, seja pelas agências de viagem, seja por propagandas veiculadas nos meios de comunicação local, sobre o país que sediaria a Copa do Mundo e os Jogos Olímpicos.

\section{A imigração haitiana e redes religiosas de acolhida}

Como já apontamos anteriormente, a chegada de haitianos na fronteira norte do Brasil, a partir de 2010, e a sua permanência naquela fronteira por vários dias, e até meses, à espera de ser atendido por um agente da Polícia Federal local colocaram um grande problema à Pastoral do Migrante, pois ela nunca tinha recebido grande contingentes de imigrantes e tampouco dispunha de estrutura para recebê-los com um mínimo de dignidade.

Com o aumento da chegada de novos imigrantes, a situação se tornou caótica no final de 2011 e início de 2012. Em dezembro de 2011, havia cerca de 1.200 haitianos; em janeiro de 2012, já eram 1.500, segundo dados da mesma Pastoral (COSTA, 2016, p. 13). Vale lembrar que, nesse mesmo mês, o governo brasileiro emitiu a Resolução $n$. 97, que determinava uma cota anual de 1.200 vistos humanitários, a serem emitidos na embaixada brasileira de Porto Príncipe. No entanto, tal medida foi recebida com pessimismo da parte 
dos imigrantes e com duras críticas de organizações não governamentais e de estudiosos da questão, sendo classificada como um retrocesso e uma forma de discriminar imigrantes, diferenciados por sua condição social ou classificação racial.

Constatada a ineficiência do regime de cotas, o governo brasileiro o revogou por meio da Resolução Normativa n. 102, em abril de 2013. O fato é que os haitianos continuavam chegando e, à medida que eram liberados em Tabatinga, seguiam de barco até Manaus, criando assim o mesmo problema para a equipe da Pastoral do Migrante daquela cidade. No início de 2012, em apenas 15 dias chegaram à capital amazonense 1.307 haitianos (COSTA, 2016, p. 28). Sem qualquer ajuda governamental, os agentes religiosos tiveram, como já foi dito, de fazer apelo à solidariedade de diversas igrejas católicas da cidade, que se ofereceram para abrigar haitianos em suas dependências ou alugar casas para recebê-los. Tal foi também o caso da ONG Ama Haiti, da Obra Social Franciscana, que abriu um abrigo para as mulheres, muitas delas grávidas. Além disso, todas puderam contar com o imprescindível apoio da Fundação Alan Kardec na oferta de alimentos, que era o grande problema naquela situação emergencial.

Outros apoios também foram oferecidos, como o ensino da língua portuguesa por instituições de ensino locais, cursos profissionalizantes pelo Centro de Ensino Tecnológico do Amazonas (Cetam) e voluntários que fortaleciam a corrente de solidariedade em prol destes imigrantes, ensinando alguma coisa, ainda que fosse confeccionar artesanato a partir de garrafas pets, em vista de uma possível geração de renda.

Para além das ações emergenciais, outras inciativas foram sendo criadas no âmbito da Pastoral, como alguns projetos de geração de renda, entre eles, a fabricação de sorvetes para serem revendidos por haitianos, cursos de culinária, um ateliê de costura e a Casa de Apoio às mães que não têm onde deixar seus filhos enquanto trabalham. Criada em 2013, essa "creche" depende de doações para funcionar e atender cerca de 24 crianças, sejam elas brasileiras, haitianas, venezuelanas ou equatorianas. Em junho de 2016, foi criada também a Casa de Passagem João Batista Scalabrini, em parceria com a Arquidiocese de Manaus, com o objetivo de atender migrantes que passam pela cidade, sejam eles haitianos, venezuelanos ou colombianos, entre outros.

Em 2014, a chegada de haitianos via Tabatinga parecia perder força, pois, segundo a mesma Pastoral, naquele ano vieram apenas 788 haitianos para Manaus (COSTA, 2016, p. 33). Contudo, tal diminuição de entradas não significava o arrefecimento desse fluxo migratório, mas sim a mudança de rota, pois a outra porta de entrada no Brasil era Brasiléia, na fronteira com o Peru e a Bolívia, onde se repetiram os mesmos problemas da falta de estrutura e de uma política de acolhimento, ainda que emergencial, da parte do Estado brasileiro. Diferentemente do Amazonas, onde os governos locais lavaram as mãos em relação a essa imigração, no Acre, o governo estadual assumiu o ônus e os riscos do gerenciamento desse fluxo migratório, que não era somente de haitianos, mas também de dominicanos, nigerianos, congoleses, entre outras nacionalidades (MAMED; LIMA, 2016). 
As cidades fronteiriças eram, na verdade, apenas lugares de passagem, pois as cidades almejadas por eles eram os grandes centros urbanos do Sudeste e do Sul do Brasil, onde as promessas de emprego eram maiores e mais atraentes do ponto de vista salarial. Nessa rota em busca de oportunidades e esperanças, outro lugar de passagem e, ao mesmo tempo, de permanência, ainda que temporária, era Porto Velho (RO), onde muitos encontraram empregos na construção das usinas hidrelétricas de Santo Antônio e Jirau, ou ainda na limpeza pública da cidade (COTINGUIBA, 2014, p. 126). Naquele município eles puderam contar também com o apoio da Pastoral do Migrante. Já em Brasiléia (AC), não há a presença dessa organização religiosa.

Com a decisão do governo do Acre de financiar a viagem de ônibus de Rio Branco para São Paulo, os problemas de acolhimento da fronteira se transferiram para a capital paulista, gerando atritos entre diferentes instâncias de governo, pois autoridades da Secretaria de Justiça de São Paulo classificaram como “irresponsável” a conduta do governo acreano, ao facilitar a vinda de 400 haitianos em apenas 15 dias (SILVA, 2015, p. 126-127). Na ausência de um plano emergencial e de estruturas para acolhê-los, novamente o ônus e a responsabilidade da acolhida dos haitianos recaíram sobre a Pastoral do Migrante, desta vez a Missão Paz, localizada no centro de São Paulo (Liberdade), onde há uma casa de acolhida mantida pelos missionários scalabrinianos. ${ }^{1}$

Essa casa, criada por Alberto R. Zambiasi em 1974, era denominada Avim - Associação de Voluntários para a Integração dos Migrantes, a qual tinha como finalidade acolher os migrantes que partiam de diferentes regiões do país em busca de trabalho na capital paulista. Localizada ao lado da Igreja Nossa Senhora da Paz, a Avim acolheu inicialmente migrantes internos, oferecendo-lhes abrigo e formação profissional, com o objetivo de facilitar sua inserção no mercado de trabalho. A partir dos anos 1980, a casa começou a receber os imigrantes oriundos do Cone Sul que, por motivos políticos ou econômicos, buscavam no Brasil a possibilidade de recomeçarem suas vidas, ainda que na "clandestinidade" (GONÇALVES; CUTTI, 2005, p. 18).

Além dos hispano-americanos, a Avim começou a acolher solicitantes de refúgio de diferentes países da América do Sul, da Europa e da África, cujo fluxo tem aumentado nas últimas décadas. Com o objetivo de oferecer uma forma mais humanizada de acolhimento, no final da década de 1990, os missionários scalabrinianos assumiram o comando da instituição e transformaram a Avim na Casa do Migrante, uma tentativa de tornar o acolhimento despersonalizado em algo mais próximo da "casa" que todo migrante deixou um dia para trás, já que para muitos deles o abrigo é o único lugar de que dispõem para permanecer temporariamente ou retornar periodicamente, sempre que o vai e vem da sobrevivência o exigir.

\footnotetext{
${ }^{1}$ Essa entidade religiosa surgiu na Itália, no final do século XIX, para acompanhar os italianos em busca do sonho de "Fare l'America", seja na América do Norte ou do Sul. Criada para atender inicialmente os italianos, esta ordem ao chegar no Brasil ampliou seu leque de atuação, acolhendo outros grupos de migrantes, internos e internacionais. Presente atualmente em 33 países, esta instituição propaga o lema de seu fundador, o bispo João Batista Scalabrini, para o qual a nacionalidade é relativa, pois “para o migrante a pátria é a terra que lhe dá o pão" (PARISE, 2016, p. 409-410).
} 
Com a chegada de tantos haitianos e africanos de diferentes nacionalidades num curto espaço de tempo, a Pastoral do Migrante começou a reivindicar do governo municipal novos espaços de acolhida na cidade. Isto porque os existentes eram insuficientes e atendem majoritariamente brasileiros em diferentes condições sociais, a saber: migrantes desempregados; população em "situação de rua"; dependentes químicos; entre outros. Nesses albergues, segundo Ana Paula, assistente social da Casa do Migrante, os imigrantes que a eles recorrem não se sentem seguros, sobretudo mulheres com crianças, que não querem correr riscos de violência sexual ou ser confundidas com "albergadas", categoria depreciativa por se relacionar a pessoas que vivem na condição de "mendicância".

Nesta queda de braço sobre as responsabilidades do acolhimento aos imigrantes em São Paulo, foi criado em 2014 no bairro da Bela Vista, pela Prefeitura paulistana, um novo espaço denominado Crai-SP (Centro de Referência e Acolhida para Imigrantes). Este centro funciona em parceria com o Serviço Franciscano de Solidariedade (Sefras) e, segundo a Coordenação de Políticas para Migrantes, é o primeiro equipamento público destinado aos imigrantes, reunindo serviços de acolhida, apoio psicológico, assistência social, orientação jurídica, formação e orientação especializada. Vale lembrar que, antes dessa experiência institucionalizada de acolhida aos imigrantes, só havia a Hospedaria do Imigrante, construída no bairro do Brás, no final do século XIX, hoje transformada no Museu da Imigração.

Ainda no âmbito da Pastoral do Migrante, outro espaço de acolhida foi criado no bairro do Pari, em 2015, pelas irmãs scalabrinianas em parceria com a Prefeitura paulistana. Os assistidos pela entidade são encaminhados diretamente pelo Centro de Referência Especializado de Assistência Social (Creas), órgão da Secretaria Municipal de Assistência e Desenvolvimento Social.

$\mathrm{Na}$ ausência de políticas públicas de acolhimento voltadas para imigrantes, sobretudo aqueles em situação de vulnerabilidade social, quando não podem contar com o apoio de alguma rede, seja ela familiar ou de amizade, a parceria público-privada parece ser uma saída. Contudo, onde tais políticas não existem, o ônus da acolhida recai sobre igrejas e organizações não governamentais que, apesar de todo esforço e dedicação, acabam fazendo o papel de mediadoras entre o mercado de trabalho e os imigrantes, tentando "disciplinar" a relação entre capital e trabalho. Um exemplo disso é o que se faz na Missão Paz em São Paulo, onde os empregadores que lá vão contratar algum trabalhador(a) devem assinar um "termo de conduta", comprometendo-se a cumprir a legislação trabalhista brasileira, o que nem sempre acontece. Do imigrante espera-se que ele aprenda alguns códigos culturais e tenha algum domínio da língua portuguesa para comunicar-se com o novo contexto.

Nessa perspectiva, a Pastoral do Migrante acabou assumindo uma dupla função: a de encaminhar para o trabalho, que deveria ser exercida por instituições públicas, como é o caso do Serviço Nacional de Emprego; e a de "regular" as relações de trabalho, tentando evitar possíveis abusos contra uma mão de obra tida como "vulnerável", por ser imigrante. E quando seus direitos não são respeitados, resta-lhes recorrer à Pastoral para que tome alguma providência, já que outros canais são, às vezes, inacessíveis em razão da burocracia 
e/ou do alto custo ou, em alguns casos, insensíveis às suas demandas. Contudo, vale notar a atuação do Ministério Público do Trabalho em algumas cidades, seja fomentando a discussão da relação entre migração e trabalho, seja atuando diretamente na resolução de conflitos (PRADO; COELHO, 2015).

Importa lembrar, porém, que o papel de redes religiosas de acolhida e de inserção sociocultural de imigrantes não é uma exclusividade do caso haitiano, já que ele foi constatado também em outros diferentes contextos, como os alemães no Sul do Brasil (SEYFERTH, 2011), os bolivianos em São Paulo (SILVA, 2003) ou os brasileiros nos Estados Unidos (MARTES, 2000).

Uma diferença, no entanto, deve ser mencionada. Se, naqueles grupos estudados, a maioria pertencia à denominação religiosa que os acolheu e os acompanhou no processo de inserção sociocultural, no caso dos haitianos isso não ocorreu, uma vez que a maioria deles declarou pertencer a alguma denominação evangélica e somente uma minoria mencionou sua adesão ao catolicismo. Um dado que chama a atenção é o fato de que apenas um dos entrevistados tenha manifestado sua adesão ao Vodu, talvez pelo fato de esta prática religiosa enfrentar forte preconceito, tanto no Haiti quanto no Brasil. Contudo, essa é uma questão que carece de estudo mais aprofundado.

A filiação religiosa desses imigrantes não constituiu, portanto, uma barreira para o acolhimento deles pela Igreja Católica, pois, para a Pastoral do Migrante, a defesa da pessoa humana e de sua dignidade antecede qualquer forma de pertencimento religioso ou condição social.

\section{Redes em processos migratórios: ambiguidades e possibilidades}

Nossa reflexão até o momento apontou a importância e o papel de diferentes redes nos processos migratórios, particularmente daquelas de cunho confessional voltadas à acolhida, como é o caso da Pastoral do Migrante. É inegável também que o trabalho humanitário realizado por ela tem sido decisivo na recepção e gestão do fluxo migratório dos haitianos, bem como de outros grupos de imigrantes que os antecederam. Falta ainda indagar em que medida essa rede de acolhida e a de outras entidades não confessionais foram agentes facilitadores da mobilidade haitiana para algumas cidades brasileiras, e quais são as implicações de atividades assumidas pela Pastoral, como é o caso da mediação para o mercado de trabalho.

Partindo do pressuposto defendido por Tilly (1990), de que "não são os indivíduos que migram, mas suas redes", denotando, dessa forma, um processo coletivo mais ou menos estruturado e pautado em lealdades morais, cabe perguntar: qual seria o grau de liberdade daquele que decide emigrar, já que a rede teria poder de direcionar o potencial migrante? Para tanto, é preciso considerar também o papel das redes que, canalizando e filtrando informações, acabarão, segundo Kelly (1995), por incidir nas decisões de potenciais migrantes na sociedade de origem. 
Se, na visão clássica, a ênfase na decisão de migrar recai sobre as condições estruturais das regiões de origem e destino, na perspectiva da rede, o papel do agente e o conjunto de suas relações são enfatizados na decisão de partir. Desse ponto de vista, o emigrante passou a ser visto como um sujeito racional que avalia custos e benefícios antes de partir, tornando-se um “agente mobilizador de seu capital social” (TRUZZI, 2008, p. 207). Nessa perspectiva, a migração é vista como um processo social aberto e sujeito a sucessivas transformações. Já na visão histórico-estrutural, ela é entendida como um processo delimitado no tempo e no espaço, com uma "origem" e um "destino" determinados, e cuja consequência, a longo prazo, seria a assimilação cultural dos emigrados e a "perda" de sua identidade étnica e cultural.

Na verdade, o que se coloca nesta discussão é como balizar o caráter “espontâneo" ou determinante da migração, sem correr o risco de, por um lado, naturalizá-lo, ou, por outro, atribuir-lhe uma determinação que confere demasiada importância a fatores estruturais. Esse dilema já fora enfrentado pelas análises clássicas e histórico-estruturais da migração, em cuja visão os fatores de "atração e expulsão" são determinantes na decisão de migrar, não restando ao indivíduo ou grupo outra saída, a não ser partir. Já na perspectiva da rede, outros fatores acabam pesando, como oportunidades disponíveis, fluxo de saída a partir de quem vai primeiro, questões legais de permanência e reunificação familiar, existência ou não de redes de apoio no destino, questões culturais, socioambientais, entre outras.

Contudo, como na maioria dos fluxos migratórios a categoria trabalho é central para entender sua origem e dinâmica, não é possível subestimar o peso que ela tem nos processos migratórios, pois, segundo Gaudemar (1977), é o capital que coloca em movimento a força de trabalho. Se ao trabalhador(a) não resta outra opção a não ser "vender a sua força de trabalho", importa perguntar em que condições isso se dá, seja na migração temporária ou permanente.

É nesse contexto desigual da relação entre capital e trabalho, em que o migrante pode tornar-se também mercadoria negociada ou traficada por redes ilegais de agenciamento, que a atuação de redes de acolhida de cunho humanitário acaba tendo um papel central, pois, seja por questões religiosas ou não, o que está em jogo é o conjunto dos direitos da pessoa humana. Nesse sentido, justifica-se a ação da Pastoral do Migrante em fazer a mediação entre empregadores e trabalhadores migrantes, garantindo-lhes minimamente direitos trabalhistas e sociais. Contudo, ao fazer este "serviço", a entidade assumiu também o risco de ser instrumentalizada pelos empregadores, que utilizaram esta rede humanitária para contratar trabalhadores(as) de que necessitavam naquele momento para a sua reprodução econômica. Embora as contratações tenham seguido os parâmetros das leis trabalhistas, os salários pagos eram, em geral, inferiores aos dos trabalhadores nacionais em igualdade de função, particularmente para os trabalhos considerados insalubres, como o realizado por haitianos e senegaleses nos frigoríficos do Sul do Brasil (MAGALHÃES, 2016, p. 517).

Assim, embora a maioria dos entrevistados não tenha atribuído um papel central à atuação de uma organização como a Pastoral do Migrante na sua chegada ao Brasil, o fato 
é que a ação dessa entidade, seja na Amazônia ou em outras cidades brasileiras, colocou em xeque a falta de uma política pública de recepção e acompanhamento de imigrantes em situação de vulnerabilidade social. A lacuna deixada pelo poder público, bem como a letargia para se tomarem medidas emergenciais, obrigou a sociedade civil a assumir o desafio de acolhê-los, com todos os seus limites e diferentes motivações. Os números de atendidos pela Pastoral do Migrante de São Paulo atestam esta afirmação: entre 2010 e 2015, 11.654 imigrantes receberam alguma forma de assistência ou orientação (PARISE, 2016, p. 413). Defensora de direitos e cidadania para os migrantes, desde a década de 1970, num contexto de restrição à liberdade de expressão e de organização, a Pastoral do Migrante tornou-se uma das instâncias de interlocução entre eles e as diferentes esferas de governo (GONÇALVES, 2005, p. 20).

No caso dos haitianos, não seria exagero afirmar que, sem a atuação da rede de acolhida católica, a experiência desses imigrantes em terras brasileiras certamente teria sido mais dramática do que realmente foi. A ampla rede de assistência e orientação foi, na verdade, mais um agente facilitador da mobilidade haitiana pelo Brasil, na medida em que eles usufruíram da sua ampla estrutura para resolver questões mais imediatas, como obter alojamento temporário, alimentação, encaminhar documentação, buscar trabalho, conseguir recursos para viagem, buscar atendimento psicológico, aprender a língua portuguesa, entre outras. A passagem deles pela Amazônia está relacionada, sobretudo, com as exigências legais do visto de entrada no Brasil, já que a não posse de tal documento os obrigou a criar uma rota alternativa de entrada no país.

Outro fator a ser considerado é a oferta de empregos pelo mercado de trabalho brasileiro, que foi mudando ao longo do tempo. Concentradas inicialmente na construção civil, particularmente para as obras da Copa do Mundo e dos Jogos Olímpicos, as propostas de trabalho foram se diversificando e tornando-se cada vez mais escassas e, ao mesmo tempo, mais exigentes.

Sem deixar de considerar os condicionamentos e controles que toda rede pode ensejar, o fato é que imigrantes, em geral, se valem de redes migratórias para realizar seus objetivos imediatos, usufruindo do que elas têm de melhor para thes oferecer. Vale lembrar, contudo, que eles não querem ser tratados como vítimas ou meros objetos de políticas oficiais, mas sim propõem-se a participar dos seus processos constitutivos. Um exemplo disso foi a participação deles em diferentes fóruns de discussão sobre a proposta de uma nova lei de imigração no Brasil, a qual foi sancionada com vetos, em maio de 2017. Nessa perspectiva, a Pastoral do Migrante tem sido um destes espaços abertos ao debate sobre diferentes questões que envolvem a migração no Brasil (SILVA, 2005, p. 25).

A formação de associações nos locais onde residem é outro exemplo de participação e de empoderamento dos haitianos, objetivando criar canais de diálogo com o contexto brasileiro, já que o Brasil é, no momento, uma das “pátrias que lhes dá o pão”, como acertadamente definem os scalabrinianos(as) a condição do migrante. Porém, não somente o pão da prosperidade material, mas também a possibilidade de trocas e recriações culturais. 


\section{Considerações finais}

Ficar, reemigrar, retornar temporariamente, "circular" entre o Brasil e o Haiti ou emigrar para outro país são possibilidades que parecem expressar as diferentes facetas da imigração haitiana no Brasil, com suas dificuldades de inserção sociocultural (FERNANDES; CASTRO, 2016, p. 480). Considerando que a imprevisibilidade e a variabilidade são elementos presentes nos processos migratórios, no caso dos haitianos também não poderia ser diferente.

Seja como forma de manutenção ou de direcionamento de fluxos migratórios, redes sociais podem ser um fator decisivo nos processos de inserção de imigrantes num novo contexto, particularmente naqueles marcados pelo preconceito de raça e classe, como é o caso brasileiro. Nesse sentido, a rede pode minorar os impactos da inserção socioeconômica e cultural, na medida em que ela acumula um "capital social”, colocando em circulação informações sobre oferta de trabalho e disponibilidade de serviços oferecidos por organizações não governamentais, como é o caso da Pastoral do Migrante.

A centralidade desta instituição no acolhimento dos haitianos no Brasil deveu-se mais à ausência de políticas públicas do que à sua especificidade religiosa, já que grande parte deles não se declarou católica. Vale notar que a passagem de muitos deles pela Pastoral não se restringiu à busca de alojamento, já que tal assistência lhes foi oferecida pela referida instituição inicialmente em momentos emergenciais, quando grandes contingentes de imigrantes chegaram à sua porta, depois que foram liberados pela Polícia Federal na Fronteira Norte. No entanto, o acolhimento oferecido aos imigrantes pela rede da Pastoral extrapola estes momentos emergenciais, abrangendo uma gama de serviços sociais, jurídicos, psicológicos, religiosos e culturais. Já da parte do Estado brasileiro, o acolhimento, com raras exceções, tem se limitado à entrega de um documento provisório ao imigrante (PEREIRA, 2016, p. 119).

Assim, nesse contexto de falta ou de limitações nas políticas públicas existentes, é notório que os serviços oferecidos pela Pastoral tenham sido considerados bons, para $46,4 \%$ dos entrevistados, e regulares, para 14,0\%. Apesar das limitações apontadas pelos próprios imigrantes, ainda assim, muitos retornam, mesmo que temporariamente, em busca de alguma orientação ou para festejar e reafirmar sua identidade nacional, étnica e cultural, como é o caso da festa da bandeira no dia 18 de maio e da independência do Haiti, no dia 01 de janeiro. Nesse sentido, a rede de acolhida católica é incorporada pelos imigrantes, independentemente de sua afiliação religiosa, e se interconecta com outras redes, atravessando fronteiras nacionais, pois eles sabem que poderão contar com este apoio, sempre que precisarem.

Enquanto alguns desses haitianos fazem projetos para o futuro no Brasil, ainda que sejam de curto prazo, outros partem para outras terras, onde certamente poderão contar com o apoio de alguma rede, seja ela migratória, familiar, religiosa ou “virtual”, pois, na chamada "aldeia global”, migrantes estão cada vez mais interconectados, compartilhando 
informações, reclamando direitos e realimentando laços afetivos, que a distância e o tempo talvez pudessem enfraquecer. Em todos os casos, é a migração fomentando novas conexões e possibilidades de múltiplas trocas.

\section{Referências}

BAENINGER, R. Migração internacional: elementos teóricos para o debate. In: BAENINGER, R. et al. (Org.). Imigração haitiana no Brasil. Jundiaí: Paco Editorial, 2016. p. 13-43.

COTINGUIBA, G. C. Imigração haitiana para o Brasil - a relação entre trabalho e processos migratórios. 2014. 154 f. Dissertação (Mestrado em História e Estudos Culturais) - Universidade Federal de Rondônia - Unir, Porto Velho, 2014.

COSTA, G. Haitianos no Brasil. In: CUTTI, D. et al. (Org.). Migração, trabalho e cidadania. São Paulo: Educ, 2015. p. 59-87.

Memória da chegada de imigrantes haitianos a Manaus, 2010-2014: presença da Pastoral do Migrante. São Paulo: CEM, 2016 (Cadernos de Migração, n. 8).

FERNANDES, D.; CASTRO, M. C. G. de. A integração na perspectiva do enriquecimento mútuo: experiências dos que emigram e os desafios dos que acolhem. In: BAENINGER, R. et al. (Org.). Imigração haitiana no Brasil. Jundiaí: Paco Editorial, 2016. p. 467-486.

FERNANDES, D.; FARIA, A. V. A diáspora haitiana no Brasil: processo de entrada, características e perfil. In: BAENINGER, R. et al. (Org.). Imigração haitiana no Brasil. Jundiaí: Paco Editorial, 2016. p. 95-111.

GAUDEMAR, J.-P. de. Mobilidade do trabalho e acumulação do capital. Lisboa: Editora Estampa, 1977.

GODOY, G. G. de. O caso dos haitianos no Brasil e a via da proteção humanitária complementar. In: RAMOS, A. de C.; RODRIGUES, G.; ALMEIDA, G. A. de (Org.). 60 anos de ACNUR: perspectivas de futuro. São Paulo: Editora CLA Cultural, 2011.

GONÇALVES, A. J.; CUTTI, D. Seminário João XXIII e Centro de Estudos Migratórios. Memória de um passado recente. Travessia, n. 52, p. 17-24, maio/ago. 2005.

HANDERSON, J. Diáspora. As dinâmicas da mobilidade haitiana no Brasil, no Suriname e na Guiana francesa. 2015. 429 f. Tese (Doutorado em Antropologia Social) - Programa de Pós-Graduação em Antropologia Social do Museu Nacional, UFRJ, Rio de Janeiro, 2015.

KELLY, P. F. Social and cultural capital in the urban ghetto: implications for the economic sociology of immigration. In: PORTES, A. (Org.). The economic sociology of immigration. New York: Russel Sage, 1995.

MAMED, L.; LIMA, E. O. de. Movimento de trabalhadores haitianos para o Brasil nos últimos cinco anos: a rota de acesso pela Amazônia Sul Ocidental e o acampamento público de imigrantes do Acre. In: BAENINGER, R. et al. (Org.). Imigração haitiana no Brasil. Jundiaí: Paco Editorial, 2016. p.113-171.

MAGALHÃES, L. F. A. Imigração haitiana no estado de Santa Catarina: contradições da inserção laboral. In: BAENINGER, R. et al. (Org.). Imigração haitiana no Brasil. Jundiaí: Paco Editorial, 2016. p. 505-524.

MARTES, A. C. B. Brasileiros nos Estados Unidos: um estudo sobre imigrantes em Massachusetts. São Paulo: Paz e Terra, 2000. 
MASSEY, D. Economic development and international migration in comparative perspective. Population and Development Review, v. 14, n. 3, p. 383-413, 1988.

MASSEY, D. et al. Worlds in motion: understanding international migration at the end of the millennium. New York: Oxford University Press, 1998.

MELO ROSA, R. de. Subjetividade e inversão do racismo: um estudo de caso sobre os haitianos na República Dominicana. Revista Interdisciplinar da Mobilidade Humana, ano XVIII, n. 34, p. 99-112, jan./jun. 2010.

PARISE, P. A Missão Paz e a acolhida a imigrantes haitianos e haitianas em São Paulo. In: BAENINGER, R. et al. (Org.). Imigração haitiana no Brasil. Jundiaí: Paco Editorial, 2016. p. 409- 425.

PATARRA, N. L. O Brasil: país de imigração? Metropolis, Revista Eletrônica de Estudos Urbanos e Regionais, ano 3, n. 9, p. 8-18, 2012.

PENTINAT, S. B. El Estatuto jurídico de protección internacional de los refugiados ambientales. Revista Interdisciplinar da Mobilidade Humana, ano XIX, n. 36, p. 11-48, jan./jun. 2011.

PEREIRA, J. C. Acolhida a migrantes e refugiados: a ética da Pastoral do Migrante e os desafios para a democracia no Brasil. Travessia, Revista do Migrante, ano XXIX, n. 79, p. 101-126, jul./ dez. 2016.

PERUSEK, G. Haitian emigration in the early twentieth century. Internacional Migration Review, v. XVIII, n. 1, p. 4-18, 1984.

PIMENTEL, M. L.; COTINGUIBA, G. C. Elementos etnográficos sobre imigração na Amazônia: inserção social de haitianos em Porto Velho. Temas de Antropología y Migración, n. 7, p. 31-55, Diciembre 2014.

PRADO, E. J. P.; COELHO, R. (Org.). Migrações e trabalho. Brasília: Ministério Público do Trabalho, 2015.

SAYAD, A. A imigração e os paradoxos da alteridade. São Paulo: Edusp, 1998.

. O retorno: elemento constitutivo da condição do imigrante. Travessia, ano XIII, número especial, janeiro 2000.

SASSEN, S. The mobility labor and capital. Cambridge: Cambridge University Press, 1988.

SCHILLER, N. G.; BARCH, L.; BLANC, C. S. From immigrant to transmmigrant: theorizing transnational migration. Anthropological Quartely, v. 68, n. 1, jan. 1995.

SEGUY, F. A catástrofe de janeiro de 2010, a "Internacional Comunitária” e a recolonização do Haiti. 2014. 399 f. Tese (Doutorado em Sociologia) - Instituto de Filosofia e Ciências Humanas da Universidade Estadual de Campinas - Unicamp, Campinas, 2014.

SEYFERTH, G. A dimensão cultural da imigração. RBCS, v. 26, n. 77, p. 47-62, outubro 2011.

SILVA, M. A. M. Pastoral dos Migrantes: peregrinos da resistência. Travessia, n. 52, p. 25-32, maio/ago. 2005.

SILVA, S. A. Haitianos em Manaus: mercado de trabalho e exercício da cidadania. In: SILVA, S. A.; ASSIS, G. O. (Org.). Em busca do Eldorado: o Brasil no contexto das migrações nacionais e internacionais. Manaus: EDUA, 2016. p.183-205.

Fronteira amazônica: passagem obrigatória para os haitianos. REMHU, ano XXIII, n. 44, p. 119-134, jan./jun. 2015.

Brazil, a new Eldorado for immigrants? The case of Haitians and the immmigration policy. Urbanities, v. 3, n. 2, p. 03-18, novembro 2013. 
. Aqui começa o Brasil: haitianos na triplice fronteira e Manaus. In: SILVA, S. A. (Org.). Migrações na Pan-Amazônia - fluxos, fronteiras e processos socioculturais. São Paulo: Hucitec/ Fapeam, 2012. p.300-322.

2003.

. Virgem/Mãe/Terra. Festas e tradições bolivianas na matrópole. São Paulo: Hucitec,

SILIÉ, R. La nueva inmigración haitiana. Santo Domingo, República Dominicana: Ediciones Flacso, 2002.

TILLY, C. Migration in modern European history. In: MCNEILL, W. H.; ADAMS, R. S. (Org.). Human migration, patterns and policies. Bloomington: Indiana University Press, 1978. p.48-72.

. Transplanted networks. In: YANS-MACLAUGHLIN, V. (Org.). Immigrayion reconsidered: history, sociology and politics. Oxford: Oxford University Press, 1990. p. 79-95.

TRUZZI, O. Redes em processos migratórios. Tempo Social, Revista de Sociologia da USP, v. 20, n.1, p. 199-218, 2008.

\title{
Sobre o autor
}

Sidney Antonio da Silva é doutor em Antropologia Social pela Universidade de São Paulo (USP). Professor do Departamento e do Programa de Pós-Graduação em Antropologia Social da Universidade Federal do Amazonas (Ufam).

\section{Endereço para correspondência}

Av. José de Arimatéia, 290, apto. 1504, Aleixo

69060-081 - Manaus-AM, Brasil

\begin{abstract}
Immigration and host networks: the case of Haitians in Brazil

This paper aims to analyze the role of host networks in the migration process of Haitians to Brazil, trying to understand the extent to which these networks played a central role in the management and communication of the issues engendered by this immigration in the country and, at the same time, if it was able of facilitating their mobility in Brazil, providing feedback to the migratory flow that began in 2010. Based on data collected from the Border, in Manaus and in some Brazilian cities, where 279 questionnaires were filled out, gathering information about the Haitian migrants present in Brazil, as well as their absent families, whether in Haiti or in another country, it was possible to build the hypothesis that without these host networks the arrival and mobility of these immigrants in Brazil would have been much more difficult than it really was, because of the lack of public policies for hosting and sociocultural insertion.
\end{abstract}

Keywords: Haitians immgration. Social networks. Brazil. 


\section{Resumen}

Inmigración y redes de acogida: el caso de los haitianos en Brasil

Este trabajo tiene como objetivo analizar el papel de las redes de acogida en el proceso migratorio de los haitianos en Brasil e indagar en qué medida esas redes han tenido un papel central en la gestión de esta inmigración y en el diálogo en torno a los problemas engendrados por ella en el país y, al mismo tiempo, evaluar en rol que ellas han tenido para facilitar la movilidad de estos migrantes en Brasil, además de retroalimentar la migración que ha sido significativa desde 2010. A partir de los datos recogidos en la frontera, en Manaus y en algunas ciudades brasileñas, donde se aplicaron 279 cuestionarios que recopilan información sobre los migrantes haitianos presentes en Brasil -así como la familia ausente, ya sea en Haití o en otro país-, fue posible construir la hipótesis de que, sin las redes de acogida, la llegada y la movilidad de estos inmigrantes en Brasil hubiera sido mucho más problemática de lo que realmente ha sido, debido a la falta de políticas públicas de acogida y de integración sociocultural.

Palabras clave: Inmigración haitiana. Redes migratorias. Acogida. Brasil.

Recebido para publicação em 12/07/2016 Aceito para publicação em 19/06/2017 
